\title{
Complementing retrofit with engagement: exploring energy consumption with social housing tenants
}

Cathrine V Jansson-Boyd ${ }^{1 *}$, Rosalyn AV Robison ${ }^{2}$, Ruth Cloherty ${ }^{1}$ and Carlos Jimenez$\operatorname{Bescos}^{3}$

${ }^{1}$ Department of Psychology, Anglia Ruskin University

${ }^{2}$ Global Sustainability Institute, Anglia Ruskin University

${ }^{3}$ Department of Engineering and Built Environment, Anglia Ruskin University

*author to whom any correspondence should be sent:

Email: cathrine.jansson@anglia.ac.uk

TEL: 08561962697

Address: Anglia Ruskin University, East Road, Cambridge CB1 1PT

\section{SUMMARY}

Councils and social housing organisations are looking to retrofit as a way to make their housing more energy efficient. Previous studies on energy use in social housing have generally focussed on the technological aspects (such as the potential savings possible by retrofitting this class of housing across the UK) or have involved one-off interventions or measures. During a two-year period, we worked with previously homeless people to reduce their energy consumption. The 32 participants lived in small blocks of flats (owned by a social housing organisation) that underwent retrofitting with air source heat pumps. We ran a three-phase tenant engagement programme to compare a range of approaches aimed at energy reduction. It was found that education, social norms, and self-awareness are all key components when it comes to initiating Environmentally Responsible Behaviours. The three approaches complemented each other, and these ought to be considered alongside technology 
provision if the aim is to reduce energy consumption. A number of reflections on the implementation of medium-term tenant engagement programmes are also presented.

Keywords: energy monitoring, transactional analysis, self-awareness, environmentalidentity, environmentally responsible behaviours

\section{INTRODUCTION}

This paper presents an overview of research conducted with previously homeless social housing tenants that was aimed at reducing their energy consumption. The study took place in a small town in Cambridgeshire, UK, from May 2012 to June 2014. The participants were all residents of supported housing association owned flats. The accommodation consisted of three blocks of flats of which two underwent a retrofit with air source heat pumps and solarphotovoltaic panels concurrently with the onset of the research.

Past studies investigating energy use in social housing have generally focussed on the technological aspects ${ }^{[1]}$ or have involved one-off interventions or measures ${ }^{[2,3]}$. This research differed in that it looked at multiple aspects to reduce energy use over a longer time-period. The research was a three-phase programme. The first phase was educational and investigated the participant's views on anthropogenic climate change and Environmentally Responsible Behaviours (ERBs). The second phase extended this initial approach to teaching specific ERBs, engaging with nature and creating community based feelings, ${ }^{[4,5]}$ whilst the third phase delivered a self-awareness intervention. To measure whether the different phases encouraged the tenants to reduce their energy consumption, qualitative methods were primarily used.

\section{Why is this work important?}


Energy use in buildings currently accounts for around $20 \%$ of global energy use ${ }^{[4]}$ and is thus associated with significant environmental impacts in terms of e.g. carbon emissions, ${ }^{[6]}$ and procurement of energy resources. Whilst commercial buildings are a very important part of this picture, ${ }^{[5]}$ in this paper our focus is on the challenges of energy use in the domestic setting, where direct control is widely spread across individual householders rather than e.g. primarily in the hands of estates managers. This is also the setting where the majority of people's "energy literacy" learning, to a greater or lesser extent, occurs. ERBs associated with domestic energy use in buildings are a commonly targeted component of campaigning, research funding (e.g. components of the EU's Horizon 2020 Energy Efficiency programme) and policy (e.g. the UK's Green Deal which aimed to make home energy efficiency improvements more financially viable). Understanding and potentially influencing domestic energy use presents a set of particular challenges within sustainable consumption research and practice. These include: (i) invisibility and lack of disaggregation (how much energy individual appliances/activities use); (ii) significant variations in perceived personal control (such as tenant vs. owner-occupier, but also members of the same household); (iii) rapid changes in the accessibility of technologies (e.g. solar PV) at the household level in recent years. Each of these has a social component which arguably has been under-represented in the approaches of national programmes to date; several of these elements we aim to address in this paper.

The significance of this research programme on energy related ERBs is two-fold and relates to the particular participant population and retrofitting technology under consideration. Firstly, the target group is not commonly researched. As far as we are aware, this is the first research programme to look at previously homeless people and ERBs related to reducing energy consumption. However, it should be noted that there have been social enterprises working in 
this space, e.g. the Oxford-based ReachAbility has worked with on environmental issues with users of homeless hostels, elderly groups, and ethnic minorities. ${ }^{[7]}$

The current work therefore provided an opportunity to formally test a different set of behavioural approaches with individuals whose voice on environmental issues and thoughts on pro-environmental behaviours is not often heard. Although there is no definitive measure of the number of homeless people in the UK - it is measured differently across local authorities - in England 112,330 households applied to their local authority for homelessness assistance in $2014 / 2015$ which corresponds to a $26 \%$ increase since $2009 / 2010$ (the picture in other nations in the UK is more mixed). ${ }^{[6]}$ There are around $3.6 \mathrm{~m}$ social housing properties in the UK (around 18\%). ${ }^{[8]}$

Those on the lowest incomes are often most at risk of fuel poverty, and potential difficulties in maintaining thermal comfort. ${ }^{[9,10]}$ They are thus a priority group when it comes to domestic energy initiatives. In order to encourage ERBs related to energy consumption it is important to understand their perspectives on the subject, both to ensure willingness to engage and improve thermal comfort.. In addition, the participants in this study were at a particular point of change within their lives, as they transitioned from supported to independent living, potentially preparing to take on home energy management themselves for the first time. Working with social housing tenants at this crucial time could, we felt, provide important insights into how different strategies may be implemented to encourage reduced energy consumption for an important wider group of householders. ${ }^{[11,12]}$

Furthermore, since the Energy White paper that was published back in $2007,{ }^{[1]}$ whereby the UK government committed to support low-carbon technologies and promote energy saving in the domestic sector, social housing providers have been encouraged to look at means to aid 
energy reduction. Air source heat pumps (ASHPs) are one such technology that have been promoted to aid decarbonisation of domestic heating in the UK. ${ }^{[3]}$ They have the potential to heat and cool buildings more efficiently than electric panel heaters, and as they are powered by electricity rather than gas they have greater potential to be run on renewable sources. However, the literature looking at the effectiveness of ASHPs as a retrofit tool is relatively sparse ${ }^{[13]}$ and has produced inconsistent results. ${ }^{[14]}$ For example, it has been found that in a domestic setting ASHP can achieve carbon savings ${ }^{[13]}$ and reduce energy bills. ${ }^{[15]}$ However one study found that while energy consumption was reduced for the majority approximately $15 \%$ of households saw an increase, ${ }^{[16]}$ Additionally, others have found that the technology does not guarantee emissions savings in office buildings ${ }^{[17]}$ or in Scandinavian homes used primarily as summer residences. ${ }^{[14]}$ The quality of installation can be highly variable, ${ }^{[18]}$ with significant effects on performance $^{[19]}$ as well as the actual cost. ${ }^{[20]}$ To make retrofit successful may also require changes in the behaviours of the people who inhabit the building. Installing new technologies does therefore not guarantee either energy savings or carbon reduction. ${ }^{[17,19]}$ In fact, it has been suggested that more energy efficient technologies may generate an increase in demand for energy services. ${ }^{[21]}$ Hence, it is important to explore how behavioural changes may complement retrofits as well as what kind of behavioural strategies work best and when to implement them.

\section{UNDERPINNNINGS OF THE THREE-PHASE PROGRAMME}

Initiating new ERBs is not straightforward. ${ }^{[22,23]}$ Over two thirds of the UK population report that they wish to change their behaviour to be more environmentally friendly, ${ }^{[24]}$ yet significant lifestyle changes are not undertaken by many. Engagement with ERBs is influenced by both external (e.g. income and home ownership) and internal (e.g. stress and habits) factors. Some studies have found ERB engagement to be more prevalent amongst people with higher education levels, however, the picture is very mixed. ${ }^{[25]}$ Studies have also found 'committed 
environmentalists' to include a greater proportion of those with no formal education than 'nonenvironmentalists'. ${ }^{[26]}$ Low income may prevent people from investing in efficiency measures, ${ }^{[27]}$ yet can also lead this group to be more energy efficient through careful use. Because of the difficulty in instigating new ERBs it is advantageous to look at the usefulness of different techniques that can be implemented to encourage engagement and commitment to energy reduction behaviours. This programme aimed to utilise and compare three approaches that could help initiate ERBs: education (largely based on the idea that people can make rational choices), building a sense of community (which is grounded in social psychology) and facilitation of self-awareness (with underpinnings from psychodynamic literature).

\section{Education}

Providing information through an educational approach is a commonly used method to encourage adoption of new pro-environmental behaviours. The hope is that information will change attitudes and the desired behaviours will follow. However, the links between information and attitude, and between attitude and subsequent behaviour, are often weak. ${ }^{[28]}$ It can be particularly difficult to change people's attitudes if there is a large discrepancy between existing beliefs and information provided. ${ }^{[29,30,31]}$ Therefore, simply providing people with information is not an effective approach in itself. ${ }^{[28,32]}$ However, an informative approach may be useful if individuals are looking for practical advice about how to reduce consumption, and may increase general awareness of the environmental issues, ${ }^{[33]}$ but is unlikely to be sufficient as a method of embedding new behaviours. ${ }^{[10]}$ Educational approaches have often been favoured when social housing organisations engage in retrofit. Such education is, more often than not, done through informative methods such as leaflets and general verbal information from housing officers. This is often later on followed by a quantitative attitude measure to test whether the information provided had been successful. 


\section{Sense of community (social norms)}

Groups matter when it comes to understanding why people change their conservation behaviours. ${ }^{[34]}$ The group to which a person feels they belong moulds his or her sense-of-self and can provide them with a sense of belonging to a community. This in turn affects their feelings and actions. ${ }^{[4]}$ The community influences their behaviour through the mediating role of group norms. ${ }^{[35]}$ The use of social norms through referencing the pro-environmental behaviours of others has been looked at in the context of encouraging ERBs. ${ }^{[36,37]}$ The situational forces that have established existing social norms in part stem from individualistic and competitive aspects of society in which self-worth is experienced in relation to consumption. ${ }^{[38]}$ Having an environmental sense-of-self has been found to be negatively correlated with an individualistic identity and positively correlated with a collective identity. ${ }^{[39,40]}$ Thus, developing a sense of community may help support the adoption of ERBs.

\section{Self-awareness}

As previously mentioned, people may not accept new information that conflicts with their existing beliefs about their self and the world. ${ }^{[29,30,31]}$ Therefore, changing people's deep seated and automatic behaviours may be most successful if it works with, rather than against, the essential values that they hold. ${ }^{[41]}$ Hence, drawing on psycho-therapeutic interventions based on increasing self-awareness through explicit discussion of values and world-views may be effective. Transactional Analysis (TA) is one framework that attempts to do this. It begins from the premise that each person is of worth and deserving of respect, making it particularly useful for working with groups that have endured difficult life situations. The goal of TA is to bring about 'constructive personality change' by enabling the part of the mind that makes 'here and 
now' decisions to make new and more constructive choices. This is achieved by exploring how beliefs are formed and incorporated into the sense of self. ${ }^{[30]}$ According to TA, people sometimes engage in behaviours which give a temporary and superficial sense of superiority. ${ }^{[42,}$ ${ }^{43]}$ In our society these behaviours are often associated with the ability to consume. ${ }^{[38]}$ Engaging in ERBs can give a sense of satisfaction and a positive sense of self. ${ }^{[44,45]}$ Thus while initially financial motivations can start the process of moving from an individualistic self-identity to a more environmental one, it may be a recognition of the positive emotions that we experience that reinforce the ERBs ${ }^{[46]}$ and establish them as the norm. ${ }^{[10,47,48]}$

There is evidence to suggest that people may need to be consciously aware of their internal environment (including the mind and how it operates) ${ }^{[30,31]}$ before they can change their interactions with their external environment. ${ }^{[49,50]}$ It has been hypothesised that understanding how our beliefs and sense of self have been shaped by society could help establish a more pro-environmental identity. ${ }^{[51,52,53,54]}$

\section{Aims of the study}

The three aforementioned approaches to achieving ERBs are very different. Education and social norms are more common concepts when it comes to generating pro-social behaviours, whilst TA is not. Hence, the three approaches make for an interesting comparison to explore whether one is more effective in encouraging social housing tenants to reduce their energy consumption. In particular, we were interested in looking at the usefulness of alternative methods, such as TA, in reaching a wider range of people. It is not uncommon that those in charge of housing associations believe that it is enough to 'educate' people in order to change tenants' behaviours so that they engage in ERBs. The research literature appears to reflect this emphasis, in that multiple approaches are not commonly used or compared. 
Each phase had a different set of objectives. During the educational phase, we wanted to: 1) establish the researcher-participant relationship and 2) begin to explore the views of this demographic group on environmental issues and ERBs. In the second phase, where we wanted to establish a sense of community, the aims were to: 3 ) explore whether it was possible to create a sense of community based on learning and engaging in ERBs, 4) create feelings of connectedness to both the group and nature, and 5) generate new social norms (engaging in ERBs) which could affect energy consumption. In the third and final self-awareness phase we wanted to: 6) explore the use of a psycho-therapeutic intervention to facilitate increased selfawareness and 7) assess whether this exploration of self-identity could help normalise ERBs.

\section{METHOD}

\section{Participants}

The researchers made contact with the participants via the on-site service manager although direct contact was made in the final phase due to staff shortage. All participating residents went through a fully informed consent procedure.

The participants consisted of 30 men and 2 women that had previously been homeless. Their ages ranged from 18 to 64 years, with a mean age of 38. During the investigative period the number of tenants that lived there at any one time varied from 22 to 32 people. Due to the nature of this potentially vulnerable population, and the fact that some residents moved on during the programme, an opportunistic sampling approach was employed. The aim was for residents to move on to their own independent housing within six months, although some resided there for longer according to need.

The participation rate for each phase varied from 42-56\%. Eight residents (numbers 4, $7,15,17,18,19,22,24)$ participated in all the engagement phases (throughout the 2 years) 
although they did not participate in every single intervention (see Table 1 for details about participation).

A large proportion of the residents had a history of alcohol and/or drug abuse alongside other mental health issues. They had been brought up in low status and income groups and their educational background was limited to National Vocational Certificate or GCSE level. None of the participants had previously had any formal education about environmentally linked issues. Some were in temporary employment and others did voluntary work.

Over half of the participants were not paying for their electricity. Instead it was included as a fixed cost in in their rent, paid by government agencies, thus was not affected by the amount of energy they used. This arrangement is not necessarily conducive to careful consumption and to the adoption of energy-conservation behaviours. It does, however, mean that short-term financial gain was not a motivating factor for the majority of residents.

\section{Procedure}

During the tenant engagement programme three different phases of behaviour change intervention were implemented and their effectiveness compared. The structure of the three engagement phases is summarised in Table 1. A wide number of qualitative research methods were employed and they took much from an 'action research' model, whereby participants help actively to co-produce lines of enquiry.

To recognise the giving of their time, participants were given a $£ 5$ supermarket voucher each time they participated. In addition, refreshments were provided at the majority of sessions. 


\section{The educational approach (phase 1)}

In the first engagement phase participants were provided with basic information about how the new heating system worked and was operated. Initially information about the heating systems was provided by the team that installed the air source heat pump. Thereafter, all educational information was provided by the researchers on this project.

This was followed by small group interviews. ${ }^{[22]}$ By discussing environmentally based issues within a group setting, participants were exposed to other perspectives, and a more indepth discussion was generated. Broad questions were employed by the researchers to enable a wide scope for the discussion within a structured context. Interview questions included "Do most people in Britain care about environmental issues?" and "Do you think it's a good idea to monitor how much energy is used in a home?" Throughout the programme individual and group interviews were recorded using a dictaphone and transcribed verbatim, with participants' permission.

A social event was then held whereby participants were given information about climate change, and undertook an exploration of ERBs associated with home energy and two team-based activities.

At the end of phase 1, individual interviews were conducted, to explore themes of personal change and adoption of ERBs.

\section{Sense of community (phase 2)}

Following on from phase 1, an educational approach was used in parallel to interventions seeking to create feelings of connectedness to both the group and nature. New residents who had not participated in phase 1 were taught how to manage the heating system. All 
participants were also taught a number of energy-saving behaviours, with group sessions utilized wherever appropriate. ${ }^{[5,35]}$

Each participant was given a Jade plant as a representation of the natural environment and to provide participants with a common focus for discussion. This was followed by a social lunch gathering a month later. Participants then worked in small groups to discuss an article on climate change, design a garden area around the block of flats where they lived, and participate in a quiz based on energy-saving behaviours.

One month later participants took part in small group interviews. They were asked 11 questions that ranged from a global to a personal perspective. Examples of questions included: "What are the consequences of burning fossil fuels to this extent do you think - for the planet's eco-system as well as for human beings?" and "What will be the personal benefits of you reducing your energy consumption on a daily basis?" The final element of phase 2 was a continuation of the garden design activity they had engaged in during the luncheon party. Participants worked in three groups to plant already sprouting daffodils and tulips, much like the ones in their designs.

\section{Self-awareness (phase 3)}

Participants were taught the basic principles of Transactional Analysis (TA) in three separate sessions, using a series of PowerPoint slides. The first two sessions outlined the basics of how the brain develops and processes information. ${ }^{[55]}$ They were also introduced to the idea that early childhood beliefs and associated emotions drive present-day behavioural responses. ${ }^{[30,31,55]}$ It was therefore emphasised that the key to changing current behaviours may be by becoming aware of early childhood influences. ${ }^{[31]}$

In the third session, participants learnt about how altruistic behaviour can lead to positive experiences such as a sense of satisfaction and feelings of belonging both within 
a community and within the environment. ${ }^{[44]}$ They were informed that a key concept within TA is the belief that our essential well-being is based on the values of reciprocity and altruism. ${ }^{[56,57]}$ Such beliefs are based on broader conceptual ideas. ${ }^{[58,59]}$ Within the context of environmentalism, it has been proposed that altruism is the equivalent of being more thoughtful about our consumption and doing the 'right' thing for ourselves and for others. ${ }^{[44]}$ It was also put to the participants that in order to establish a pro-environmental identity, it is important to realign people with their essential values. ${ }^{[41,44,46]}$ This can be done by becoming aware of the beliefs that were projected onto them at an early age from an individualistic and competitive society. ${ }^{[42,60,61]}$

The sessions were structured using an environmental-based framework so that the self-awareness information was directly linked to ERBs. For example, when explaining about how we learn from observing others, this was done by providing examples different ERBs that others engage in. There was also a post-assessment phase where participants' understanding and views of TA, and any subsequent changes they had made relating to ERBs, were assessed.

\section{Quantitative Research Methods}

Whilst this programme of study was focussed on exploring ERBs and possible energy reduction qualitatively, some quantitative data was collected to see if it would support the qualitative findings. This was done through energy data monitoring and a questionnaire that measured general attitude towards the environment.

Throughout the tenant engagement programme energy consumption for the individual dwellings within the three blocks of flats was monitored using Current Cost EnviR Smart meters ${ }^{[62]}$ and clamps on 17 electricity meters within the flats. A smart meter was also installed in each of the blocks of flats by an independent company. Data was collected 
manually from both the smart meters and the electricity meters. The internal temperature of each flat was collected using LogTag temperature data loggers. ${ }^{[63]}$ The energy consumption data was then normalised according to both the internal and external conditions in order to generate an energy index. The normalisation process to generate the energy index was done by combining the meter reading in $\mathrm{kWh}$ and the degree days in accordance to the internal temperature. $^{[64]}$

The questionnaire was constructed using statements that were deemed to measure pro-environmental attitudes. The statements were presented to 16 undergraduate students at a university in the UK, who commented on their suitability for inclusion in the scale. The items were then edited for appropriate wording and content validity was undertaken, resulting in a 69-item questionnaire. Cronbach's alpha and a principal axis exploratory factor analysis with oblimin rotation were applied resulting in 17 -items with a coefficient $\alpha$ of 0.88 . The recommended reliability coefficient value should be 0.7 or above. ${ }^{[65]}$ This resulted in three factors: one measured whether the participants 'Generally cared for the environment'; the second measured if 'Small contributions' are important; and the third looked at whether they felt personally 'Responsible' for the environment. All factors had a loading of above 0.7 . The questions were measured using a seven-point Likert scale. Likert scales are commonly used to measure attitudes and opinions. ${ }^{[66,67,68]}$ The questionnaire was used throughout the project for comparison to the energy consumption and qualitative data collected, in particular at the start and end of each phase.

\section{DATA ANALYSIS \& RESULTS}

Thematic analysis was used to analyse the interview and focus group data, following Braun and Clarke's three cycle process. ${ }^{[69]}$ In phase 1, NVivo (software specifically designed for qualitative analysis) was used to analyse the data whilst in phase 2 and 3 a manual approach 
was taken. The analysis of data from the tenant engagement programme generated one key theme per phase. Here we will outline and discuss the themes based on observation and the qualitative interview data.

\section{Comprehension and dialogue: Phase 1}

In the first group interviews of the engagement programme, we found participants willing to engage in dialogue around environmental and energy issues. They were also "happy to talk about and engage with different issues, when the conversation was brought to them and they were provided with prompts for topics of discussion or encouragement to follow-up on their initial comments." ${ }^{[22]}$ This helped with the first aim in this phase, to establish a good researcher-participant relationship, something that was crucial for the continuing success of the research programme. It was also helpful in achieving the second aim, which was to begin to explore their views on ERBs. Participants showed that they had existing knowledge of a wide variety of relevant topics (in particular steps commonly promoted in campaigns, like switching appliances off standby), and any presumption that this demographic group would have little to say on, or little interest in, global issues such as climate change would be quite wrong. It was also found that they understood the importance of well communicated information in promoting ERBs as well as the benefits that may be gained by teaching people early in life. ${ }^{[2]}$ The latter can be seen through the comment that "they learn this at schools nowadays, which I think is a good thing”.

Despite a clear awareness, participants often felt they lacked the authority to determine what the best course of action might be regarding particular energy consuming activities. Therefore, one conclusion drawn from phase 1 was that "a change of emphasis from solely increasing people's knowledge to increasing people's confidence in their existing knowledge, and their own ability to gain knowledge and become more informed, may be 
effective in enabling active behavioural choices." [22] This may also help with managing or overcoming some of the barriers (as they perceived them) that the participants stated as reasons for finding it difficult to act on environmental issues, including habit, self-interest and lack of agency. ${ }^{[22]}$

The first phase highlighted two additional key points. Firstly, that the participants had considered the wider implications of their own and others' behaviours. They themselves identified, without explicit prompting, the importance of social norms in developing behaviours. "Many of the participants had noticed specific actions of others, and had remembered them, therefore acknowledging that our own actions have implications beyond their immediate consequence." ${ }^{\text {[22] }}$ Secondly, it was identified that follow-on activities which included a self-reflective element might be fruitful, since "many of the specific examples given by participants which helped lend insight arose when they had the time and space to reflect on these issues". ${ }^{[22]}$ Dialogue, rather than simply a one-way flow of information, was crucial throughout the programme to allow the participants to repeatedly reflect on ERBs and in particular energy consumption.

\section{Growing involvement: Phase 2}

Overall the participants' attitudes towards energy conservation at the start of phase 2 appeared to be somewhat negative. Although there was some evidence that the participants were engaging in some of the energy-and-money saving behaviours, many seemed to agree that there was no point in engaging in ERBs because any action that they took as individuals would be inconsequential. Several participants also mentioned that if they were to change their behaviours this would only be if it was 'worthwhile' in terms of saving money. It was considered more important for industry to reduce its consumption of electricity and 
subsequent pollution. Steve was quite angry about the way individuals are being held accountable whilst in his view industry was the main polluter and contributor to climate change.

Steve: "Well I think personally, I think industry should hold more sway than the single person leaving his telly on standby, turning his tap off in between brushing his teeth and spitting out the toothpaste sort of thing, you know? I think that, that big industries, big conglomerates should be held more responsible than, as a people, you know, as a person."

There was also evidence of a negative social influence from others who seemed to waste energy: Bob voiced his concern that engaging in ERBs seemed pointless when other people did not seem to care if they were wasting energy. The participants also reflected on whether they would personally benefit from engagement in ERBs and they seemed to agree that any effort they put in would mainly be benefitting future generations. This was evident from comments made by Bob and Steve.

Bob: "There is nothing personal for us now, it would be in the future that would be ....."

Steve: “Not personal benefits, no (inaudible) it's more our children or our children'schildren, you know."

Towards the end of phase 2, participants were more positive about their engagement in the programme. They expressed a clear liking for the social gathering where they had first and runner-up prizes attached to each activity. The prizes positively reinforced their engagement with the environment and reinforced a sense of group achievement. The final activity of 
phase 2 involved planting shrubs. Participants were in charge of the planting activity in terms of organisation and design and appeared excited and happy, with several participants thanking the researchers afterwards. That group belongingness was taking place during phase 2 is clear from the qualitative data collected: participants showed consensus in how they were viewing ERBs, and there were indications that tenants were thinking of themselves as an 'ingroup' in that their behaviours appear insignificant in comparison to 'others'. Comparing yourself to other groups is typical of those who feel they belong to an established group. ${ }^{[5,35]}$ Participants also reported that being a part of a group made them look at their own behaviours more rather than (as John said) trying to "shift the blame onto someone else".

\section{Understanding the importance of behaviour change: Phase 3}

There appeared to be mixed feelings amongst the participants for the sessions involving TAbased methods. At the onset, some were very enthusiastic whilst others seemed sceptical. During the individual interviews in phase 3, following the self-awareness sessions, several participants shared more of their life story, in an in-depth and personal manner. And halfway through the TA sessions it became apparent that the participants particularly enjoyed this phase when one of them commented that "today's session was very interesting and can give you a very good knowledge of using your brain more frequently and in different ways".

At the end of this phase, most tenants reported having reduced their electricity consumption by being more conscientious and engaging in the specific energy-saving behaviours that they had learnt. Bob and Ian attribute this shift in behaviour to the project. 
Bob: "Well frankly before doing this project I used to have my things on stand-by twenty-four seven, you know, all day and had lights on and now I turn them off and I actually consider what I am using."

Ian: "Well attending the course has helped because it has given me a better understanding of what I can do to lower my energy I use."

It is clear that these new behaviours have meaning for them in a satisfying and enjoyable way. Nine out of the ten participants stated they were only using the energy that they needed and they felt good about it. They also felt inspired to tell others. There was also a shift in attitude and they were more able to take personal responsibility for the amount of energy they used. They were willing to do it even though it may not make a significant difference to the environment. However, some of them believed that individual contributions do make a difference as is notable from Simon and Carl's comments.

Simon: "Yes I think if every person does their own little bit then it will improve the environment or help."

Carl: "Oh right, well, um, it's like a movement moving forward. If, if everybody starts, like, to make a change and you continue to make a change yourself, you know that in the long run it's going to benefit, going to benefit all of us. And hopefully it will have that knock on effect which obviously we want it to be doing; in having everyone, everyone would be re-wired to be doing like the things that should be done." 
The last comment, made by Carl, also reflects the teachings of TA. This is evident when he says that "everyone would be re-wired to be doing like the things that should be done" as they were taught that they can change the way they think, feel and behave. There were also other comments that indicated that the TA sessions had been processed. Several participants made specific comments that were essentially altruistic. Paul saw humans engaging in ERBs as essential for other life forms and the diversity of the planet. Carl was concerned with the planet and for future generations.

Paul: "Not just animals, diversity, rain forests stuff like that."

Carl: "Okay, yeah I do believe that it is very important to be environmentally friendly, um, as in the long run, it will have, um, um, the I'm sure it will have a knock on effect and in years to come we can make our environment either greener or we can reduce on pollution, um, yeah I think it's important for our next generation."

Some tenants reported an increase in self-awareness and linked this to a better understanding of their behaviour as well as guiding new behaviours. Three of the eight participants in the group interviews, following the end of phase 3, mentioned feeling they were leaders by example and that their efforts would inspire others. Paul was very concerned about the threat to diversity and the natural environment. He had been one of the quietest participants throughout the project so it was unusual for him to be so vocal in the focus group discussion.

Paul: "What I am saying is that we should, we can lead by example, and if it's seen that we can make the changes then people will follow suit." 
The data from phase 3 reflects the transition these men have taken on their journey to becoming bio-centric individuals. By the end of phase 3 the participants were actively engaging in ERBs and used the previously provided material to make new decisions about how they wanted to behave. Whilst money was partially a motivating factor in the second phase, the majority of participants appeared to be motivated by altruistic values which was a strong feature in the interviews that took place after the self-awareness intervention. They were motivated by an altruistic concern for future generations as well as for natural diversity. Some of the participants had also felt motivated to tell others and to lead by example which are key indicators that they had adopted a pro-environmental self-identity. ${ }^{[41,44]}$ However, there was also an additional theme that kept cropping up, that overlapped with a theme in phase 1 , namely education. One participant said, when reflecting on why he seemed to have internalised the importance reducing his energy consumption, that he thought "it is education, and to understand how much we do affects the environment." Thus, indicating that the different phases complement each other.

\section{Additional support for the qualitative findings}

The main aspect of this project was to explore tenants' thoughts, feelings and attitudes to energy saving behaviours through qualitative means. However, we also undertook some supplementary measures across the three phases: we assessed the tenants' pro-environmental attitudes through a questionnaire and monitored their energy use through smart metering.

Based on the eight participants that took part in the entire engagement programme, the questionnaire revealed differences in the mean value for 'Generally caring for the environment' (as can be seen in Table 2). At the onset the mean was 4.9 out a possible 7 and during the last phase it measured 5.5. This indicates that the particpants began with proenvironmental attitudes overall, although this was not extremely strong. This raises the 
possibility that they were, from the beginning, amenable to the idea of decreasing their energy consumption. As can be noted from Table 2 the overall mean for all three factors tested had increased by the end of the third phase. It was, however, only the mean difference for how personally 'responsible' the participants felt that was found to be significant. As this particular attitude measure went up gradually throughout the two phases it appears that building feelings of belonging to a group was the starting point for genuine change which was then increased by the engagement in self-awareness sessions. Towards the end, it did also seem as if several participants experienced an almost instantaneous insight (an 'aha' moment) as to how their own behaviour affects the environment.

\section{Insert Table 2 here}

The measure of responsibility was compared against the energy index. However, due to some of the difficulties in consistent monitoring of energy consumption we could only directly compare the energy index to overall attitudes for ten participants during phase 2 and 3 . It was found that there was a significant linear relationship between feeling responsible for the environment $(\mathrm{p}=0.003, \mathrm{r}=0.891)$ and the energy index. This relationship can be seen in Figure 1. These results support the qualitative findings and are consistent with the theme of feeling a sense of responsibility. However, the limitation of the small sample should be taken into account and is conferred in the conclusion.

Despite the small sample size, it was possible to obtain data from two identical flats in different blocks, one that had the air source heat pump installed (Flat A) and another that had 
not (Flat B) for the period between October 2013 and June 2014 (phase 3 of the tenant engagement programme). As well as being the same size, these flats had the same number of tenants (one in each flat) throughout this time period. The data found no significant difference in energy consumption between the two flats compared (see Figure 2). This could indicate that retrofit alone may not guarantee energy savings and provide some support to previous suggestions that there is a human factor involved in decreasing the use of energy. ${ }^{[14]}$ Hence, a tenant engagement programme may be a solution (or at least a partial solution) in reducing energy consumption. However, with comparable data from only two flats this is not conclusive evidence but warrants further investigation. There are also a number of other variables that may account for lack of significant difference between the two flats such as the behaviour of the tenants in the flats compared, e.g. window opening patterns, that are known to affect the effectiveness of the installed heating systems. An overview of the findings from this research programme can be seen in Figure 3.

\section{Insert Figure 3 here}

\section{CONCLUSIONS}

This project was motivated by the retrofit of two (out of three) blocks of adjacent social housing flats. The aim of the tenant engagement programme was to explore a number of different approaches to facilitating ERBs in this specific population. We embarked on this task, in phase 1, by exploring what this population already knew about issues relating to anthropogenic climate change and perceived barriers to engaging in pro-environmental behaviours, together with providing general information on these topics. Their general attitude towards the environment was also measured using a repeated questionnaire throughout the programme. In phase 2, we provided information on more specific ERBs in 
parallel with trying to create a sense of community. This was done in part by establishing common 'ground' to connect the tenants, in particular through group activities that provided some connection to nature such as the garden design and planting sessions. Having laid the foundations for ERBs, self-awareness sessions were delivered in phase 3. It was considered that having basic awareness of programming and the neural processes that take place to formulate the sense of self ${ }^{[30,31]}$ might empower participants to change habitual and automatic non-environmental behaviours and adopt more constructive and satisfying ERBs. TA was the framework that was used to facilitate this process as well as to provide an antidote to the destructive nature of downward comparison. ${ }^{[42,43,70,71]}$

It was apparent from the interviews conducted in the first and second phase that this group of society have a broad understanding of the consequences of anthropogenic climate change. There were however expressions of a degree of being powerless to affect it. Furthermore, it was evident that (as is found across the general population) they were often aware of what they and others did that was not environmentally responsible. However, they did not necessarily feel able to change their behaviour. A number of perceived barriers were identified by participants to explain this, including lack of knowledge and lack of agency that any action they took as an individual might make no impact.

A central contribution of this paper was its focus on a distinctive group of social housing tenants, those that have previously been homeless, whose homes (social housing) represent a significant proportion of properties likely to be targeted for retrofit. Key findings concluded that each of the three phases strongly complemented each other and, crucially, relied on each other. The participants themselves also recognised the importance of the three phases in altering their energy related behaviours. Furthermore, a growing sense of positive participant involvement with the programme was observed over the two-year period. 
Supporting this, the mean values compared for three factors measured on the attitude scale demonstrated a small but significant increase in feeling 'Responsible for the Environment' throughout the programme. It was further found that the ten tenants that took part in both phase 2 and 3 reduced their energy consumption in line with feeling increasingly responsible for the environment. However, as with any correlational relationship, it is not causational and therefore further research should explore this relationship to rule out other possible influencing variables.

The continuous use of qualitatively based methods throughout the project ensured that our participants had the opportunity to state how they genuinely felt, and gave participants a voice. It also provided them with the opportunity to ask questions and bounce ideas off other participants (such as in group interviews). Essentially, it ensured that they felt they were being listened to. A recurring theme throughout the three phases is that the participants really enjoyed having the opportunity to engage in discussions where their opinion mattered. This tenant engagement programme, over two years, afforded the opportunity to develop an in-depth programme where each element built on the previous ones; many shorter term interventions are unable to do this.

As with any research, there were a number of limitations present which we discuss here. Firstly, the three phases were (necessarily) conducted consecutively. Due to the small size of the sample population it was not possible to implement the approaches in isolation and therefore establish the success of the different strategies in their own right. It can be difficult, in studies such as these, to implement control groups; in this case this would have involved access to a second building undergoing a retrofit which had a similar population, size, and location etc. . Gaining access to vulnerable groups such as those that have been previously homeless is difficult and it is even more difficult to source those in similar accommodation to 
those included in this study. However, we note the value this would hold in future studies. This study worked with a sample of 32 residents overall, with each individual intervention involving smaller numbers. This is a reasonable sample size for qualitative data collection, which forms the basis of this paper, but does limit the generalizability of statistical results. However, for the purpose of this study the quantitative data is merely used in support of the qualitative data and it is not suggested that it ought to be considered in its own right. Larger scale studies would be needed to confirm these effects. The medium term nature of this project, whilst one of its strengths, means it cannot be excluded that there may have been external influences (e.g. mainstream media reports) which affected participants' willingness to engage in ERBs at different points. Additionally, the fact that the majority of the participants were male, and that the researchers who delivered the engagement programme were all female, may have influenced our results. In particular gender can affect group dynamics, and this would be an interesting area of exploration in future studies. As with any interview-based study there is always the possibility that participants were telling the interviewer what they thought they wanted to hear. The results from the questionnaire, however, do indicate that an attitude shift did occur towards the environment with the largest change seen in personal responsibility. Finally, we note that some difficulties were encountered in the energy consumption monitoring, due to the inadvertent removal of clamps and loggers at various points, and the occasional loss of wireless connections. In addition, since residents were able to use their own appliances, including plug-in electrical heaters, it was not always possible to separate out heating from other electricity consumption. This is in part why results presented here only cover a portion of the engagement programme.

We note here reflections on the delivery of the programme itself, as we learnt a number of valuable lessons. It is important to deliver this type of programme with the utmost respect for the participants. The researchers asked for feedback on a frequent basis and 
participants were responsive to this approach. As explored in a previous paper, ${ }^{[22]}$ humour was often used by participants, and helped create an atmosphere conducive to the opening up of potentially difficult topics. When working with groups involving potentially vulnerable individuals, aspects such as trust, confidentiality and willingness to participate should be considered carefully. It took considerable time and effort to build up a relationship with some of the participants so that they felt comfortable meeting with us on their own; during the early stages some had a chaperone with them. Even though a good 'relationship' was established with our participants there were still times when they did not wish to or could not take part. Of course we respected this but this is a further factor which may impact on the results of this and similar studies.

The results confirm that coming from a low status, low income background with minimal or no formal qualifications is no barrier to establishing a pro-environmental selfidentity and ultimately change their ERBs. Retrofit is an important, and necessary, contributor when it comes to reducing building energy consumption - in particular in countries like the UK with an ageing housing stock. However, it is essential to take the enduser into account as they may be the determining factor in regards to whether energy reduction takes place. Hence, we propose that retrofit needs to be done in parallel with tenant engagement. Ideally, tenant engagement programmes should sit alongside retrofits of social housing. Though, it may be worth considering that it can be effective for social housing organisations to implement a tenant engagement programme on its own. Investing in groupbased environmental programmes that facilitate a sense of belonging to a group and selfawareness is an effective way to establish enduring ERBs and possibly even proenvironmental identity. Therefore, policy should wherever possible consider the impact that 'social' factors may play in meeting reduced energy targets. 
We set out to determine which one of three tenant engagement approaches would be most effective in reducing overall energy consumption. However, it was found that they all strongly complemented each other through the interplay between them. Education can provide the starting point for people to reflect on good environmental practice and what obstacles they perceive to be holding them back. This then provides a platform on which they can work with others to consider their priorities as a group, or within wider society. These are strengthened by opportunities for self-reflection. Future studies may wish to test the three approaches in a way that allow for more direct comparison. A common theme throughout the three phases was that they gave participants a voice. When given the opportunity to discuss how they think and feel, people are able to consider their own needs and feelings in a wider context.

\section{Acknowledgements}

This study was funded by the European Regional Development Fund (ERDF). We would like to thank them as well as all those who have directly or indirectly been involved in this project, including Tony, Lynn, Cambridgeshire County Council, Luminus Group and Fenland District Council. We also thank the three anonymous reviewers who improved earlier versions of this paper.

\section{Conflict of interest}

The authors declare no conflict of interest.

\section{References}

1. Jenkins DP. The value of retrofitting carbon-saving measures into fuel poor social housing. Energy Policy 2010; 38, 832-839. 
2. Jenkins D, Middlemiss L, and Pharoah R. A study of fuel poverty and low-carbon synergies in social housing. Published online: http://www.ukerc.ac.uk/ 2011

3. Chahal, S., Swan, W., and Brown, P. Tenant perceptions and experiences of retrofit. In Proceedings of Retrofit 2012 Conference. University of Salford, Salford 2012; 2426.

4. Tajfel H and Turner JC. An integrative theory of intergroup conflict. In Austin WG and Worchel S (eds) The social psychology of intergroup relations, Monterey, CA: Brooks-Cole, 1979, pp. 33-47.

5. Van Prooijen JW, Van den Bos K, Wilke HAM. Group belongingness and procedural justice: Social inclusion and exclusion by peers affects the psychology of voice. Journal of Personality and Social Psychology 2004; 87, 66-79.

6. Jenkins DP. The value of retrofitting carbon-saving measures into fuel poor social housing. Energy Policy 2010; 38, 832-839.

7. Ramsden, S. Transformation Fund Final Project Report: Climate Reach; ReachAbility: Oxford, UK, 2010.

8. Boait P J. Fan D, and Stafford A. "Performance and control of domestic groundsource heat pumps in retrofit installations." Energy and Buildings 2011; 43, 19681976.

9. Kollmuss A and Agyeman J. Mind the Gap: Why do people act environmentally and what are the barriers to pro-environmental behavior? Environ Educ Res 2002; 8: 239 260.

10. Abrahamse W. Steg L, Vlek CT. et al. A review of intervention studies aimed at household energy conservation. J Environ Psychol 2005; 25: 273-291.

11. Schäfer M, Jaeger-Erben M, and Bamberg S. Life events as windows of opportunity for changing towards sustainable consumption patterns? Results for an intervention study. J Consum Policy 2012; 35: 65-84.

12. Verplanken B. Old habits and new routes to sustainable behaviour. Engaging the Public with Climate Change: Behaviour Change and Communication, 2011; 17-30.

13. Kelly, N. J., and J. Cockroft. "Analysis of retrofit air source heat pump performance: Results from detailed simulations and comparison to field trial data." Energy and Buildings 2011: 43; 239-245.

14. Gram-Hanssen, K. Christensen, T.H. and P.E. Petersen Air-to-air heat pumps in reallife use: Are potential savings achieved or are they transformed into increased comfort? Energy and Buildings, 2012; 53: 64-73.

15. Jenkins, D. P. The value of retrofitting carbon-saving measures into fuel poor social housing. Energy policy 2010; 38, 832-839.

16. Raynaud, M. Osso, D. Bourges B. et al. Evidence of an indirect rebound effect with reversible heat pumps: having air conditioning but not using it? Energy Efficiency 2016; 9: 847-860.

17. Jenkins, D., R. Tucker, M. Ahadzi, and R. Rawlings. The performance of air-source heat pumps in current and future offices. Energy and Buildings 2008: 10, 1901-1910.

18. Dikici A. and Akbulut A. Exergetic performance evaluation of heat pump systems having various heat sources. Int. J. of Energy Res 2008; 32, 1279-1296

19. Haas R and Biermayr P. The rebound effect for space heating empirical evidence from Austria. Energy Policy 2000; 28, 403-410.

20. Gustafsson, .S-I and Karlsson, B.G. Why is life-cycle costing important when retrofitting buildings. Int. J. of Energy Res 1988; 12, 233-242. 
21. Ehrhardt-Martinez, K and Laitner, J.A. Rebound, Technology and People: Mitigating the Rebound Effect with Energy-Resource Management and People-Centred Initiatives. ACEEE Summer study on Energy Efficiency in Buildings. 2010; 7-76 - 791.

22. Robison R AV and Jansson-Boyd CV. Perspectives on Sustainability: Exploring the Views of Tenants in Supported Social Housing. Sustainability 2013; 5, 5249-5271.

23. Gifford R. The dragons of inaction: psychological barriers that limit climate change mitigation and adaptation. Am Psychol 2011; 66, 290-302.

24. Gifford R. The dragons of inaction: psychological barriers that limit climate change mitigation and adaptation. Am Psychol 2011; 66, 290-302.

25. Van Liere K D and Dunlap R E The Social Bases of Environmental Concern: A Review of Hypotheses, Explanations and Empirical Evidence The Public Opinion Quarterly 1980; 44, 181-197.

26. Barr S, Gilg AW, Ford N. The household energy gap: Examining the divide between habitual-and purchase-related conservation behaviours. Energy Policy 2005; 33, 1425-1444.

27. Emmel JM, Lee H J, Cox RH. et al.. Low-income households' response to higher home energy costs. Fam Consum Sci Res J 2010; 38, 372-386.

28. Staats H. Understanding pro-environmental attitudes and behaviour: An analysis and review of research based on theory of planned behaviour. In Bonnes $\mathrm{M}$, Lee $\mathrm{T}$, Bonaiuto M (eds) Psychological theories for environmental issues. Aldershot, UK: Ashgate, 2003, pp.171-202.

29. Cacioppo, J. T. Petty, R. E. Kao, C. F. et al. Central and peripheral routes to persuasion: An individual difference perspective. J of Personal and Soc Psych, 1986; $51,1032-1043$

30. Hood B. The self-illusion. London: Constable, 2012.

31. Kahneman D. Thinking, fast and slow. London: Penguin Books, 2011.

32. Hines JM, Hungerford HR, Tomera AN. Analysis and synthesis of research on responsible environmental behaviour: A metaanalysis. J Environ Educ 1986/87; 18: $1-8$.

33. Staats H, Harland P, Wilke HAM. Effective durable change: A team approach to improve environmental behaviour in the household. Environ Behav 2004; 36(3): 341367.

34. 36. Stern PC. What psychology knows about energy conservation. Am Psychol 1992; 47(10): 1224-1232.

35. Terry DJ and Hogg MA. "Group norms and the attitude-behaviour relationship: A role for group identification," Pers Soc Psychol Bull 1996; 22 (8): 776-93.

36. Cialdini RB. Crafting normative messages to protect the environment. Curr Dir Psychol Sci 2003; 12(4): 105-109.

37. Cialdini RB and Goldstein NJ. Social influence: compliance and conformity. Annu Rev Psychol 2004; 55: 591-621.

38. Kanner AD and Gomes ME. The all-consuming self. In Rosak T, Gomes AD, Kanner GA (eds) Ecopsychology: Restoring the earth, healing the mind. Sierra Club: San Fransisco, USA, 1995, pp. 77-91.

39. Clayton S and Opotow S. Justice and identity: Changing perspectives on what is fair. Pers Soc Psychol Rev 2003; 7(4): 298-310. 
40. Milfont TL and Sibley CG. The hierarchy enforcement hypothesis of environmental exploitation: A social dominance perspective. J Exp Soc Psychol 2014; 55: 188-193. 29

41. Steg L, Bolderdijk JM, Keizer K. et al.. An integrated framework for encouraging pro-environmental behaviour: The role of values, situational factors and goals. $J$ Environ Psychol 2014; 38: 104-115.

42. Fein S and Spencer S. Prejudice as self-image maintenance: Affirming the self through derogating others (1997). In Stangor C (ed) Stereotypes and prejudice. Hove, East Sussex: Psychology Press, 2003.

43. Billig M. Prejudice, categorization and particularization: From a perceptual to a rhetorical approach. Eur J Soc Psychol 1985; 15: 79-103.

44. De Young R. Expanding and evaluating motives for environmentally responsible behaviour. Journal of Social Issues 2000; 56(3): 509-526.

45. Perkins HE. Measuring love and care for nature. J Environ Psychol 2010; 30: 455463.

46. De Young R. Some psychological aspects of reduced consumption behaviour. The role of intrinsic satisfaction and competence motivation. Environ Behav 1996; 28: 358-409.

47. Stern PC. Psychology and the science of human-environment interactions. Am Psychol 2000; 55: 523-530.

48. Jansson-Boyd CV. Consumption matters. Basingstoke, Hampshire: Palgrave Macmillan, 2011.

49. Shultz PW. Empathizing with nature: The effects of perspective taking on concern for environmental issues. Journal of Social Issues 2000; 56(3): 391-406.

50. Mayer FS and Frantz CM. The connectedness to nature scale: A measure of individuals' feeling in community with nature. J Environ Psychol 2004; 24(4): 503515.

51. Christopher JC. Situating psychological well-being: Exploring the cultural roots of its theory and research. J Couns Dev 1999; 77(2): 141-152.

52. Christopher JC, Richardson FC, Christopher SE. Philosophical hermeneutics: A metatheory to transcend dualism and individualism in western psychology. From an earlier published symposium: In Smith KD (chair) Metatheories in the Natural Sciences and in Cross-Cultural Psychology. Symposium conducted at the International Congress of the International Association for Cross-Cultural Psychologists, Warsaw, Poland. 2000.

53. Gilbert P. Compassion focused therapy. London: Routledge, 2010.

54. Ryle A and Kerr IB. Introducing cognitive analytic therapy: Principles and practice. Chichester, West Sussex: John Wiley \& Sons Limited, 2002.

55. Berne E. Transactional analysis: A new and effective method of group therapy. Am J Psychol 1958; 12: 735-743.

56. Ummet, D. Eksi, H.and M. Mustafa. Altruism among University Students: A Study of Transctional Analysis Ego States and Life Satisfaction. Anthropologist, 2015; 3, 625635.

57. Law, G. Mind, Body, Soul and Spirit in Transactional Analysis: An Integral Approach to Relationships. Malvern: Impact 2006.

58. Rogers, C.R. Client-centred therapy. Oxford: Houghton Mifflin 1951. 
59. Seligman, M. and Mather, P. Authentic Happiness: Using the New Positive Psychology to Realize Your Potential for Lasting Fulfilment. New York: Free Press. 2002.

60. Milfont TL and Duckitt J. The structure of environmental attitudes: A first- and second-order confirmatory analysis. J Environ Psychol 2004; 24: 289-303.

61. Milfont TL, Richter I, Sibley CG. et al.. Environmental consequences of the desire to dominate and be superior. Pers Soc Psychol Bull 2013; 39(9): 1127-1138.

62. Retrieved from the Internet on April $4^{\text {th. }}$ http://www.currentcost.com

63. Retrieved from the Internet on April $4^{\text {th }}$ : http://www.logtag.co.uk

64. Jimenez-Bescos C. The development of an energy index to assess energy reduction. Proceedings of the first International Sustainable Ecological Engineering Design for Society (SEEDS) Conference 2005; 559-562.

65. Nunnally, J.C. 1978 Psychometric Theory, $2^{\text {nd }}$ ed, New York: McGraw-Hill.

66. Bowling, A. Research Methods in Health. Buckingham: Open University Press, 1997.

67. Burns, N. \& Grove, S.K. The practice of Nursing Research Conduct, Critique \& Utilization. Philadelphia: W.B. Saunders and Co, 1997.

68. Likert, R. A Technique for the Measurement of Attitudes. Archives of Psychol, 1932; $140,1-55$.

69. Braun V and Clarke V. Using thematic analysis in psychology. Qual Res Psychol 2006; 3: 77-101.

70. Festinger L. A theory of social comparison processes. Hum Relat 1954; 7, 117-120.

71. Wills T A. Downward comparison principles in social psychology. Psychol Bull 1981; 90: 245-271. 
Table 1. Tenant engagement programme details

\begin{tabular}{|c|c|c|c|}
\hline & $\begin{array}{l}\text { Phase } 1 \text { (May } 2012 \text { - Nov } \\
\text { 2013) }\end{array}$ & $\begin{array}{l}\text { Phase } 2 \text { (Nov } 2013- \\
\text { Feb 2014) }\end{array}$ & $\begin{array}{l}\text { Phase } 3 \text { (Mar } 2014- \\
\text { Jun 2014) }\end{array}$ \\
\hline Overall aim & $\begin{array}{l}\text { Educational: provision } \\
\text { of information about } \\
\text { ASHPs, climate change, } \\
\text { ERBs; initial exploration } \\
\text { of participants' views. }\end{array}$ & $\begin{array}{l}\text { Sense of community: } \\
\text { focus on group identity } \\
\text { building. Sense of } \\
\text { belonging in nature via } \\
\text { plant activity / garden } \\
\text { design. }\end{array}$ & $\begin{array}{l}\text { Self-awareness: } \\
\text { psycho-therapeutic } \\
\text { intervention, exploring } \\
\text { participants' } \\
\text { environmental self- } \\
\text { identity. }\end{array}$ \\
\hline $\begin{array}{l}\text { Participant } \\
\text { activities } \\
\text { (chronological } \\
\text { order, no. of } \\
\text { participants } \\
\text { given in brackets) }\end{array}$ & $\begin{array}{l}\text { - Group interviews }(4,3, \\
2 \text { participants, } 30-45 \\
\text { mins). } \\
\text { - Individual heating } \\
\text { system briefings }(11,10 \\
\text { mins). } \\
\text { - Social gathering with } \\
\text { informational } \\
\text { activities/games on } \\
\text { climate change and ERBs } \\
\text { ( } 12,90 \text { mins) } \\
\text { - Individual interviews } \\
\text { (5,23-45 mins) }\end{array}$ & $\begin{array}{l}\text { - Heating system } \\
\text { briefing (new tenants) } \\
\text { - Small group } \\
\text { discussions on ERBs } \\
\text { - Jade plant } \\
\text { stewardship activity } \\
\text { - Social gathering with } \\
\text { group activities incl. } \\
\text { design of a garden area } \\
\text { at the flats } \\
\text { - Groups interviews (3, } \\
\text { 2, } 6 \text { participants, 40-57 } \\
\text { mins). } \\
\text { - Team gardening, as } \\
\text { per design activity }\end{array}$ & $\begin{array}{l}\text { - Three presentations } \\
\text { on: how the brain } \\
\text { processes information, } \\
\text { how we formulate a } \\
\text { sense of self, how } \\
\text { people form } \\
\text { worldviews. } \\
\text { - Individual interviews } \\
\text { (10 participants who had } \\
\text { attended presentations, } \\
12-37 \text { mins) }\end{array}$ \\
\hline $\begin{array}{l}\text { Participants in }>1 \\
\text { element (no.s } \\
\text { given) }\end{array}$ & $\begin{array}{l}23 \text { residents }(1-19,22-24, \\
31)\end{array}$ & $\begin{array}{l}20 \text { residents }(1-7,15, \\
17-22,24,26-29,32)\end{array}$ & $\begin{array}{l}9 \text { residents }(4,7,15,17- \\
19,22,24,25)\end{array}$ \\
\hline
\end{tabular}


Table 2. Means for environmentally held attitudes

\begin{tabular}{|c|c|c|}
\hline Measure & $\begin{array}{c}\text { First } \\
\text { (mean value) }\end{array}$ & $\begin{array}{c}\text { Last } \\
\text { (mean value) }\end{array}$ \\
\hline $\begin{array}{c}\text { Generally caring for the } \\
\text { environment }\end{array}$ & 4.9 & 5.5 \\
\hline Small contributions & 4.04 & 5.01 \\
\hline Responsibility & 3.9 & $4.7^{*}$ \\
\hline
\end{tabular}

*Statistically significant $p=0.006$

Table 2 show the mean values for the environmentally held attitudes as tested using a questionnaire. The mean values were taken from the first (start of phase 1) and last (end of phase 3) set of questionnaires. 


\section{Figure 1. Relationship between energy consumption and feelings of responsibility}

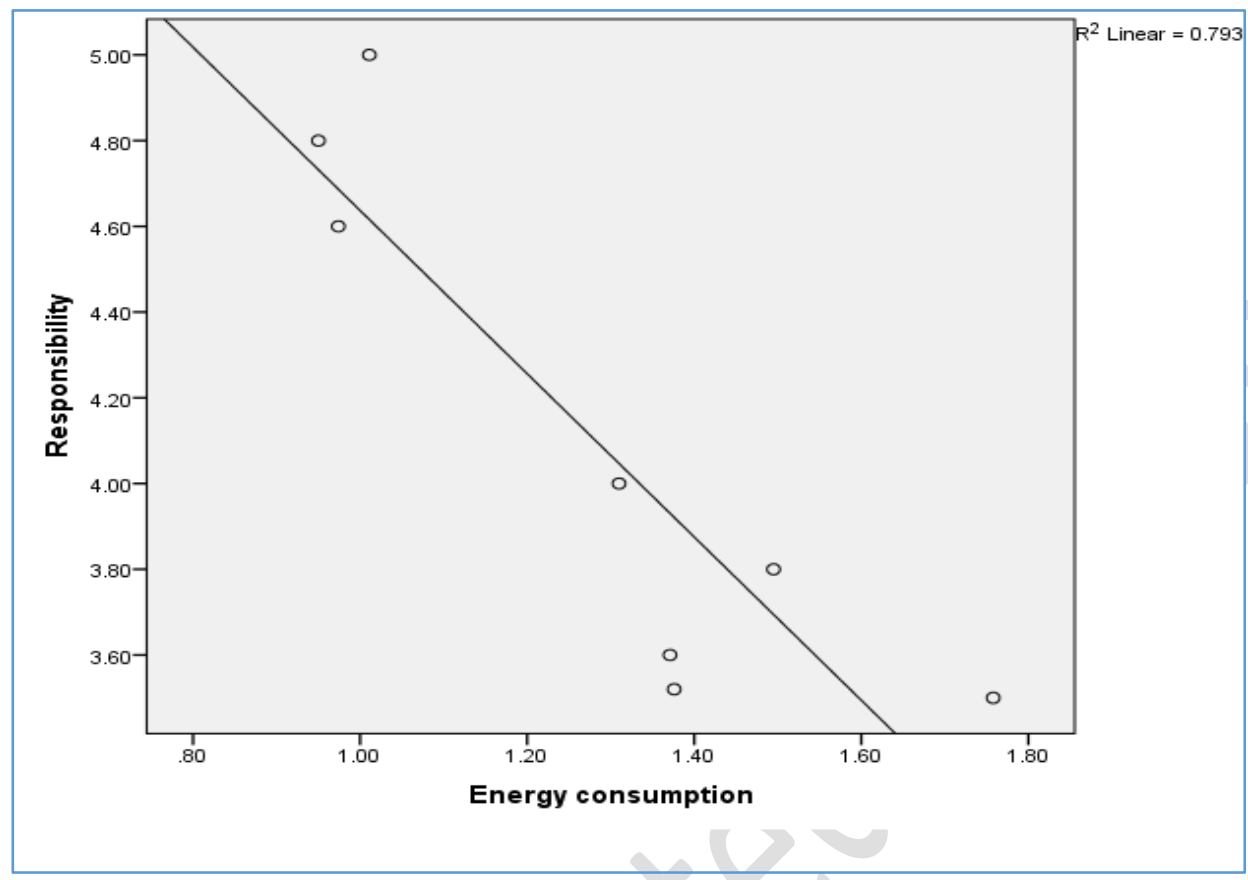

Figure 1 shows the relationship between overall energy consumption between Oct 2013 and

Jun 2014 and feeling responsible for the environment. It shows a significant linear relationship between feeling responsible for the environment $(\mathrm{p}=0.003, \mathrm{r}=-0.891)$ and energy index. The energy index is calculated normalising the energy consumption with degree days in accordance to the internal temperature. The relationship is based on data from 10 participants that took part in both phase 2 and 3. Four of the participants lived in shared dwellings ( 2 tenants in each) and hence the figure shows data for 8 flats. 
Figure 2. Energy index for two flats between October 2013 and June 2014 (phase 3).

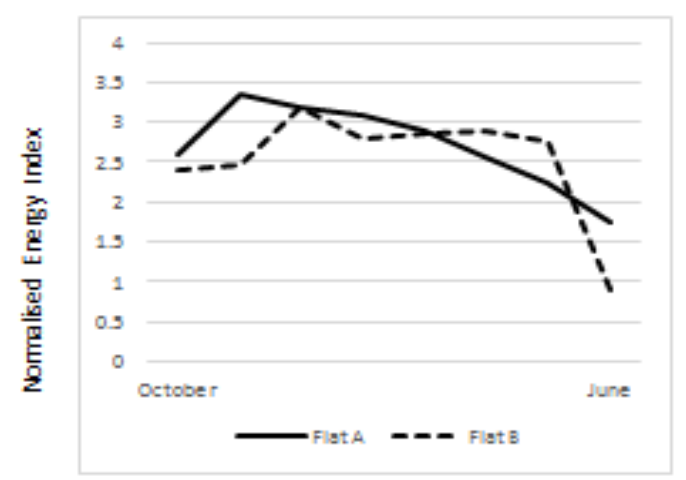

Figure 2 shows little difference in energy consumption between these comparable flats, and that the resident of Flat B, with panel heaters, sometimes used less energy than the resident of Flat A, with an air source heat pump. Thus, the importance of user behaviour is highlighted, and of complementing retrofit (a vitally important aspect of effective building energy reduction programmes) with tenant engagement. 